\title{
Cardiovascular History
}

National Cancer Institute

\section{Source}

National Cancer Institute. Cardiovascular History. NCI Thesaurus. Code C66921.

A record of a patient's medical background reg arding cardiovasular disease. 